American Journal of Applied Sciences 6 (6): 1264-1269, 2009

ISSN 1546-9239

(C) 2009 Science Publications

\title{
Weighted Semi-Blind Channel Identification by Cross Relation Method
}

\author{
${ }^{1}$ Mohamed Tahar Taba and ${ }^{2} \mathrm{~S}$. Femmam \\ ${ }^{1}$ LAIG Laboratory, Guelma University, Algeria \\ ${ }^{2}$ LACSC Laboratory, ECE Paris, France
}

\begin{abstract}
Problem statement: The bandwidth efficiency of many communication systems could be improved if the transmission channel was estimated blindly without resort to training sequences. GMSK was a spectrum-efficient modulation scheme and it was adopted as the modulation standard of GSM systems. Approach: However, because of its phase modulation, Gaussian filtering and partial response signalling properties, Results: The simulation results showed great potential of semi-blind identification algorithms, since we used no extra antenna or over-sampling the received signal. Conclusion: GMSK was not a linear modulation. Linear approximation of the GMSK signal made the blind equalization system model applicable for GSM. In the sequel, a linear approximation of GMSK signals was presented and a blind GSM and semi-blind channel identification algorithm based on the cross relation method was suggested.
\end{abstract}

Key words: Cross-relation, GMSK, blind identification, semi-blind identification, GSM channel, diversity

\section{INTRODUCTION}

The Pan-European cellular standard of GSM uses a Time Division Multiple Access (TDMA) scheme, where each frequency band is shared by 8 users allocated with 8 time slots. During each time slot (approximately $0.577 \mathrm{~ms}$ ), a 142 bit burst is transmitted, in which two 58 bit streams of information data are separated by a training midamble. The 26 bit training sequence can be used by receivers to identify the unknown linear channel impulse response that includes transmitter filter, physical channel and receiver filter. This training sequence represents a sizable overhead that reduces the overall system efficiency. If blind/semi-blind equalization can eliminate part of the entire training overhead while maintaining the system performance at an acceptable level, it can significantly improve the system efficiency.

In this study, we first present a new blind channel identification algorithm based on the cross relation method $^{[1]}$. We note that blind channel identification algorithms based on SOS are sensitive to channel order mismatch ${ }^{[2]}$, which is very common in wireless environment.

GMSK approximation: The impulse response of the Gaussian LPF $h(t)$ is:

$$
h(t)=\frac{\sigma}{B \sqrt{2 \pi}} \exp \left(\frac{-\sigma^{2}}{2} t^{2}\right)
$$

where, $\sigma=\frac{2 \pi \mathrm{B}}{\sqrt{\ln 2}}$, with BT $=0.3$ for GSM. B is the 3 $\mathrm{dB}$ bandwidth of the filter. The square pulse response $\mathrm{g}(\mathrm{t})$ of the Gaussian LPF is:

$$
g(t)=h(t) * \operatorname{rect}\left(\frac{t}{T}\right)
$$

where, the rectangular function $\operatorname{rect}(\mathrm{x})$ is defined by:

$$
\operatorname{rect}\left(\frac{\mathrm{t}}{\mathrm{T}}\right)= \begin{cases}1 / \mathrm{T}, & \text { for }|\mathrm{t}|<\frac{\mathrm{T}}{2} \\ 0, & \text { Otherwise }\end{cases}
$$

The pulse response $\mathrm{g}(\mathrm{t})$ can be written as:

$$
g(t)=\frac{1}{2 T}\left[\mathrm{Q}\left(2 \pi \mathrm{BT} \frac{\mathrm{t}-\mathrm{T} / 2}{\mathrm{~T} \sqrt{\ln (2)}}\right)-\mathrm{Q}\left(2 \pi \mathrm{BT} \frac{\mathrm{t}+\mathrm{T} / 2}{\mathrm{~T} \sqrt{\ln (2)}}\right)\right]
$$

where, $\mathrm{Q}(\mathrm{t})$ is the $\mathrm{Q}$-function:

$$
\mathrm{Q}(\mathrm{t})=\frac{1}{\sqrt{2 \pi}} \int_{\mathrm{t}}^{\infty} \exp \left(-\tau^{2} / 2\right) \mathrm{d} \tau
$$

Consequently, the continuous phase modulation (CPM) pulse is the integral: 


$$
\psi(t)=\int_{-\infty}^{t} g(\tau-2 T) d \tau^{\prime}
$$

In GSM system, the GMSK parameter BT $=0.3$ is chosen so that:

$$
\psi(\mathrm{t}) \approx\left\{\begin{array}{lc}
0, & \mathrm{t} \leq 0 \\
1, & \mathrm{t} \geq 4 \mathrm{~T} .
\end{array}\right.
$$

The baseband signal of GMSK modulation is:

$$
s(t)=\exp \left[j \frac{\pi}{2} \sum_{n=-\infty}^{\infty} \alpha_{n} \psi(t-n T)\right]
$$

In witch $\alpha_{n}= \pm 1$ is the binary data for transmission. Because, existing blind equalization algorithm rely on linear system models, linear approximation of the GMSK signal becomes the necessary first step. Following the approach used in $^{[1]}$ for linear QAM approximation of the GMSK signal used in GSM, we take the first approximation step:

$$
\begin{aligned}
& s(t)=\exp \left[j \frac{\pi}{2} \sum_{n=-\infty}^{\infty} \alpha_{n} \psi(t-n T)\right] \\
& \approx \exp \left(j \frac{\pi}{2} \sum_{k=-\infty}^{n-4} \alpha_{k}\right) \prod_{k=n-3}^{n} \exp \left[j \frac{\pi}{2} \alpha_{k} \psi(t-k T)\right]
\end{aligned}
$$

\section{$\mathrm{T} \varepsilon[\mathrm{nT},(\mathrm{n}+1) \mathrm{T})$.}

Equation 7 becomes the basis of linear approximation. It can be seen that there are 16 different terms in the product expansion of (7). Among the 16 different linear pulses, however, only two pulses are significant while the others are nearly all zero. Retaining these two most significant pulses, the linear approximate model for GMSK with $\mathrm{BT}=0.3$ is:

$$
s(t)=\sum_{n=-\infty}^{\infty} a_{0, n} h_{0}(t-n T)+\sum_{n=-\infty}^{\infty} a_{1, n} h_{1}(t-n T)
$$

Where:

$$
\begin{aligned}
\mathrm{a}_{0, \mathrm{n}} & =\exp \left[\mathrm{j} \frac{\pi}{2} \sum_{\mathrm{n}=-\infty}^{\mathrm{n}} \alpha_{\mathrm{n}}\right]=\mathrm{j}_{\alpha_{\mathrm{n}} \mathrm{a}_{0, \mathrm{n}-1}} \\
& =-\alpha_{\mathrm{n}} \alpha_{\mathrm{n}-1} \mathrm{a}_{0, \mathrm{n}-2} \\
\mathrm{a}_{1, \mathrm{n}} & =\mathrm{j}_{\alpha_{\mathrm{n}}} \exp \left[\mathrm{j} \frac{\pi}{2} \sum_{\mathrm{n}=-\infty}^{\mathrm{n}} \alpha_{\mathrm{n}}\right]=\mathrm{j}_{\alpha_{\mathrm{n}} \mathrm{a}_{0, \mathrm{n}-2}}
\end{aligned}
$$

In other words, the GMSK signal can be approximated with almost no error by the sum of two
QAM signals with pulse shapes $\mathrm{h}_{0}(\mathrm{t})$ and $\mathrm{h}_{1}(\mathrm{t})$. These two pulses in the linear approximation are shown in Fig. 1.

For the case $\mathrm{L}=4, \mathrm{BT}=0.3$ :

$$
\begin{aligned}
& \mathrm{h}_{0}(\mathrm{t})=\beta(\mathrm{t}-4 \mathrm{~T}) \beta(\mathrm{t}-3 \mathrm{~T}) \beta(\mathrm{t}-2 \mathrm{~T}) \beta(\mathrm{t}-\mathrm{T}) 0 \leq \mathrm{t} \leq 5 \mathrm{~T} \\
& \mathrm{~h}_{1}(\mathrm{t})=\beta(\mathrm{t}-\mathrm{T}) \beta(\mathrm{t}-2 \mathrm{~T}) \beta(\mathrm{t}-4 \mathrm{~T}) \beta(\mathrm{t}+\mathrm{T}) 0 \leq \mathrm{t} \leq 3 \mathrm{~T}
\end{aligned}
$$

With:

$$
\beta(t)=\left\{\begin{array}{lr}
\frac{\sin [\pi \mathrm{h}-\pi \mathrm{h} \psi(\mathrm{t})]}{\sin (\pi \mathrm{h})}, & \mathrm{t} \varepsilon[0, \mathrm{LT}) \\
\beta(-\mathrm{t}), & \mathrm{t} \varepsilon(\mathrm{LT}, 0] \\
0, & |\mathrm{t}| \geq 0
\end{array}\right.
$$

With $\mathrm{h}=0.5, \beta(\mathrm{t})$ becomes:

$$
\begin{aligned}
\beta(t)= & \left\{\begin{array}{lc}
\cos \left(\frac{\pi}{2} \mathrm{~g}(\mathrm{t})\right) & \mathrm{t} \varepsilon[0, \mathrm{LT}) \\
\beta(-\mathrm{t}), & \mathrm{t} \varepsilon(\mathrm{LT}, 0] \\
0, & |\mathrm{t}| \geq 0
\end{array}\right. \\
\psi(\mathrm{t})= & \frac{1}{2}+\frac{\mathrm{t}_{1} \mathrm{Q}\left(\sigma \mathrm{t}_{1}\right)-\mathrm{t}_{2} \mathrm{Q}\left(\sigma \mathrm{t}_{2}\right)}{2 \mathrm{~T}_{\mathrm{p}}}-\ldots \\
& -\frac{\exp \left(-\sigma^{2} / 2\right) \mathrm{t}_{1}^{2}-\exp \left(-\sigma^{2} / 2\right) \mathrm{t}_{2}^{2}}{2 \mathrm{~T}_{\mathrm{p}} \sigma \sqrt{2 \pi}} \\
\mathrm{t}_{1}= & \mathrm{t}-\frac{\mathrm{T}_{\mathrm{p}}}{2}, \mathrm{t}=\mathrm{t}_{2}+\frac{\mathrm{T}_{\mathrm{p}}}{2}, \sigma=\frac{2 \pi \mathrm{B}}{\sqrt{\ln 2}}
\end{aligned}
$$

where, $T_{p}$ is Sampling period.

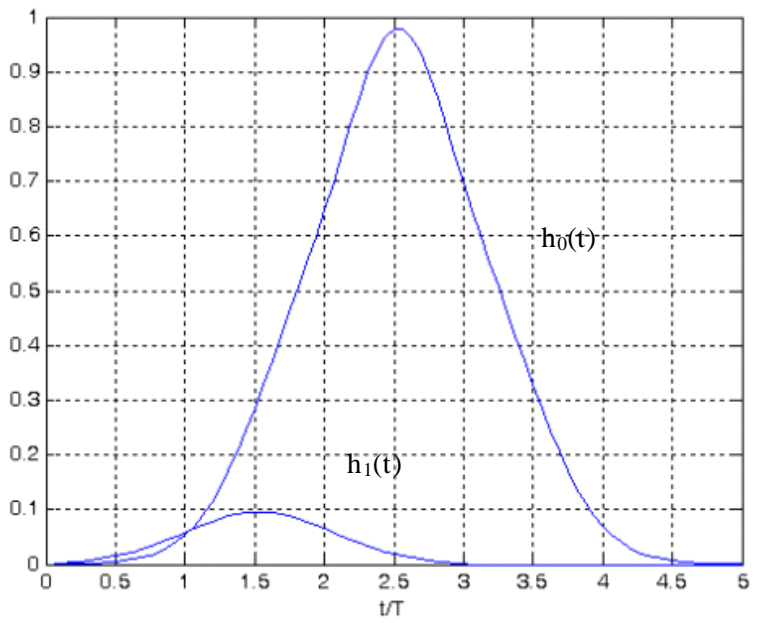

Fig. 1: Represents two pulse shapes in the GMSK linear approximation. The power in $\mathrm{h}_{1}(\mathrm{t})$ is $0.48 \%$ of the power in $\mathrm{h}_{0}(\mathrm{t})$ 


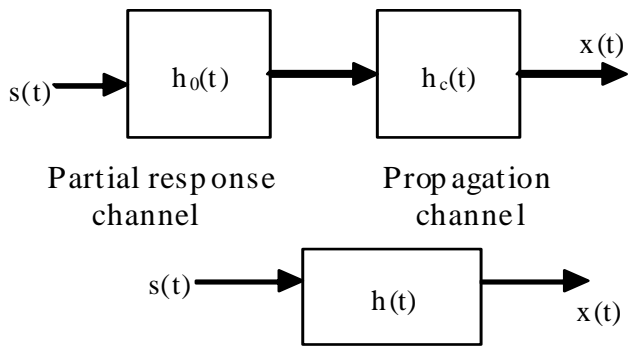

Fig. 2: The composite channel response $h(t)$ for equalizers

Because the majority (99.5\%) of signal energy in GMSK signal $s(t)$ is contained in the first pulse approximation $\mathrm{h}_{0}(\mathrm{t})$ Fig. 2, we can further simplify $\mathrm{s}(\mathrm{t})$ into a single QAM transmission:

$$
s(t)=\sum_{n=-\infty}^{\infty} a_{n} h_{0}(t-n T), \quad a_{n}=j \alpha_{n} a_{n-1}
$$

It can be noted that the approximation error may be viewed as an additive interference. Therefore, even in noiseless channels, the maximum Signal-to-Noise Ratio (SNR) of this approximation is at $23 \mathrm{~dB}^{[2]}$. with this linear QAM Quaternary Phase Shift Keying (QPSK) approximation, existing blind equalization methods can be applied.

For a physical channel impulse response $h_{c}(t)$ the combined linear approximation pulse is simply:

$$
\mathrm{h}(\mathrm{t})=\mathrm{h}_{\mathrm{c}}(\mathrm{t}) * \mathrm{~h}_{0}(\mathrm{t})
$$

The received GMSK signal is approximately:

$$
x(t)=\sum_{k=-\infty}^{+\infty} h(t-k T) s(k)+n(t)
$$

where, $n(t)$ is channel noise. The baud rate sampled discrete signals and responses are defined as:

$$
x_{i}=x(i T), \quad h_{i}=h(i T), \quad n_{i}=n(i T)
$$

The channel output sequence is thus a stationary sequence:

$$
\mathrm{x}_{\mathrm{n}}=\sum_{\mathrm{k}=0}^{\mathrm{L}} \mathrm{h}_{\mathrm{k}} \mathrm{a}_{\mathrm{n}-\mathrm{k}}+\mathrm{n}_{\mathrm{n}}
$$

Channel diversity: For the single QPSK approximation of the GMSK signal, only sampling at higher than the baud rate will not generate the necessary channel diversity needed in all SOS methods for blind equalization due to the lack of excess bandwidth in the approximate pulse shape $\mathrm{h}_{0}(\mathrm{t})$. Naturally, one can create channel diversity by adding antennas. Unfortunately, additional antenna unit requires extra RF receiver and significantly increases the hardware cost. Here we show how to reduce hardware cost by processing the received data so that two channel outputs can be extracted from a single received GMSK signal.

We observe that $a_{n}=j \alpha_{n} a_{n-1}$ in the linear QPSK approximation of GMSK. However, the relationship actually indicates that at any given time, $a_{n}$ can only select two values instead of four. Hence, $a_{n}$ is a pseudoQPSK and is realized by rotating a BPSK signal:

$$
a_{n-k}=j^{n-k}\left(\prod_{1=k-3}^{M+L-1} \alpha_{n-1}\right)\left(\alpha_{n-M-L} j^{M+L-n}\right)
$$

Without loss of generality, let $\left(\alpha_{n-M-L} j^{M+L-n}\right)$ be purely real (or imaginary). Then:

$$
\begin{aligned}
\mathrm{a}_{\mathrm{n}-\mathrm{k}} & =\mathrm{j}^{\mathrm{n}-\mathrm{k}} \tilde{\mathrm{a}}_{\mathrm{n}-\mathrm{k}}, \quad \tilde{\mathrm{a}}_{\mathrm{n}-\mathrm{k}}= \pm 1, \\
\mathrm{k} & =0, \ldots, \mathrm{M}+\mathrm{L}-1
\end{aligned}
$$

To extract channel diversity from the singlechannel system (16), signal pre-processing based on special characteristics of the pseudo-QPSK input is necessary. Equation 16 can be transformed as:

$$
\begin{aligned}
\mathrm{x}_{\mathrm{n}} & =\sum_{\mathrm{k}=0}^{\mathrm{L}} \mathrm{h}_{\mathrm{k}} \mathrm{j}^{\mathrm{n}-\mathrm{k}} \tilde{\mathrm{a}}_{\mathrm{n}-\mathrm{k}}+\omega_{\mathrm{n}} \\
& =\sum_{\mathrm{k}=0}^{\mathrm{L}}\left[\mathrm{h}_{\mathrm{k}} \mathrm{j}^{\mathrm{n}-\mathrm{k}}\right] \tilde{\mathrm{a}}_{\mathrm{n}-\mathrm{k}}+\omega_{\mathrm{n}}
\end{aligned}
$$

As a result, we can obtain a new (derotated) sequence:

$$
\begin{aligned}
\tilde{\mathrm{x}}_{\mathrm{n}} & =\mathrm{x}_{\mathrm{n}} \mathrm{j}^{-\mathrm{n}} \\
& =\sum_{\mathrm{k}=0}^{\mathrm{L}}\left[\mathrm{h}_{\mathrm{k}} \mathrm{j}^{-\mathrm{k}}\right] \tilde{\mathrm{a}}_{\mathrm{n}-\mathrm{k}}+\mathrm{j}^{-\mathrm{n}} \omega_{\mathrm{n}}
\end{aligned}
$$

Derotation not only changes the GMSK detection into a simpler BPSK detection problem, it can also create channel diversity useful in blind equalization ${ }^{[1]}$.

Since $\left\{\tilde{a}_{n}\right\}$ is real-valued sequence, we can induce two sub-channel outputs from (20): 


$$
\begin{aligned}
& x_{n}^{1}=\operatorname{Re}\left\{\tilde{x}_{n}\right\}=\sum_{k=0}^{L} \operatorname{Re}\left[h_{k} j^{-k}\right] \tilde{a}_{n-k}+\operatorname{Re}\left[j^{-n} \omega_{n}\right] \\
& x_{n}^{2}=\operatorname{Im}\left\{\tilde{x}_{n}\right\}=\sum_{k=0}^{L} \operatorname{Im}\left[h_{k} j^{-k}\right] \tilde{a}_{n-k}+\operatorname{Im}\left[j^{-n} \omega_{n}\right]
\end{aligned}
$$

where, the common input is a BPSK signal, i.e.:

$$
\tilde{a}_{\mathrm{n}}=\mathrm{j}^{-\mathrm{n}} \mathrm{a}_{\mathrm{n}}= \pm 1
$$

From the BPSK input data sequence, two subchannels can be generated without over-sampling and extra antenna:

$$
\left\{h_{k}^{1}\right\}=\left\{\operatorname{Re}\left(h_{k} j^{-k}\right)\right\} \quad \text { and } \quad\left\{h_{k}^{2}\right\}=\left\{\operatorname{Im}\left(h_{k} j^{-k}\right\}\right.
$$

We hence arrive at the familiar equation in SIMO (Single Input/Multiple Output) models:

$$
\mathrm{X}[\mathrm{k}]=\mathrm{Ha}[\mathrm{k}]+\mathrm{n}[\mathrm{k}]
$$

Where:

$$
\mathrm{x}[\mathrm{k}]=\left[\begin{array}{c}
\operatorname{Re}\{\mathrm{x}[\mathrm{k}]\} \\
\operatorname{Im}\{\mathrm{x}[\mathrm{k}]\}
\end{array}\right], \mathrm{H}=\left[\begin{array}{c}
\operatorname{Re}\{\mathrm{H}\} \\
\operatorname{Im}\{\mathrm{H}\}
\end{array}\right], \mathrm{n}[\mathrm{k}]=\left[\begin{array}{c}
\operatorname{Re}\{\mathrm{n}[\mathrm{k}]\} \\
\operatorname{Im}\{\mathrm{n}[\mathrm{k}]\}
\end{array}\right]
$$

$\mathrm{H}$ will have full column rank if $\left\{\operatorname{Re}\left(\mathrm{h}_{\mathrm{k}} \mathrm{j}^{-\mathrm{k}}\right)\right\}$ and $\left\{\operatorname{Im}\left(\mathrm{h}_{\mathrm{k}} \mathrm{j}^{-\mathrm{k}}\right\}\right.$ share no common zeros ${ }^{[2]}$.

Cross-relation method: Consider a SIMO system of $\mathrm{q}$ outputs given by:

$$
\mathrm{y}(\mathrm{l})=\sum_{\mathrm{k}=0}^{\mathrm{M}} \mathrm{h}(\mathrm{k}) \mathrm{s}(\mathrm{l}-\mathrm{k})+\mathrm{n}(\mathrm{l})
$$

The noise free outputs $y i(k), 1 \leq \mathrm{i} \leq \mathrm{q}$ are given by:

$$
\mathrm{yi}(\mathrm{k})=\mathrm{hi}(\mathrm{k}) * \mathrm{~s}(\mathrm{k}), 1 \leq \mathrm{i} \leq \mathrm{q}
$$

where, * denotes convolution. Using commutativity of convolution, it follows:

$$
\mathrm{hj}(\mathrm{k}) * \mathrm{yi}(\mathrm{k})=\mathrm{hi}(\mathrm{k}) * \mathrm{yj}(\mathrm{k}), 1 \leq \mathrm{i}<\mathrm{j} \leq \mathrm{q}
$$

This is a linear equation satisfied by every pairs of channels. It was shown ${ }^{[3]}$ that based on $\mathrm{q}(\mathrm{q}-1) / 2$ possible cross-correlation, the channel parameters can be uniquely identified. By collecting all possible pairs of q channels, one can easily establish a set of linear equations. In matrix form, this set of equations can be expressed as:

$$
\mathrm{Y}_{\mathrm{q}} \mathrm{h}=0
$$

where, $\mathrm{Y}_{\mathrm{q}}$ is defined by:

$$
\begin{gathered}
\mathrm{Y}_{2}=\left[\mathrm{Y}_{(2)},-\mathrm{Y}_{(1)}\right] \\
\mathrm{Y}_{1}=\left[\begin{array}{cccc} 
& \mathrm{Y}_{(1-1)} & & 0 \\
\mathrm{Y}_{(1)} & & 0 & -\mathrm{Y}_{(1)} \\
& \bullet & & \bullet \\
& \bullet & & \bullet \\
0 & & \mathrm{Y}_{(1)} & -\mathrm{Y}_{(1-1)}
\end{array}\right]
\end{gathered}
$$

With $1=3, \ldots, \mathrm{q}$ and:

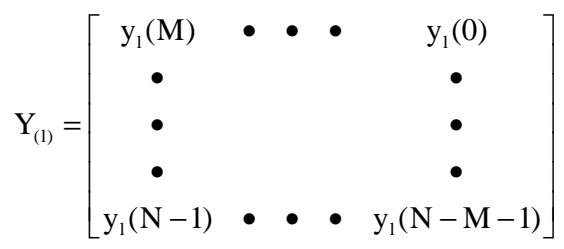

In the presence of noise, Eq. 26 can be naturally solved in the Least-Square (LS) ${ }^{[3]}$ sense according to:

$$
\hat{\mathrm{h}}_{\mathrm{CR}}=\arg \min _{\|\mathrm{h}\|=1} \mathrm{~h}^{\mathrm{H}} \mathrm{Y}_{\mathrm{q}}^{\mathrm{H}} \mathrm{Y}_{\mathrm{q}} \mathrm{h}
$$

We now present simulation results of GSM blind identification. A GMSK pulse of four symbols was generated and bandwidth $\mathrm{BT}=0.3$. The bit rate is $270 \mathrm{~kb} \mathrm{sec}^{-1}$.

Figure 3 shows the estimation of the propagation channel by the cross-relation method.

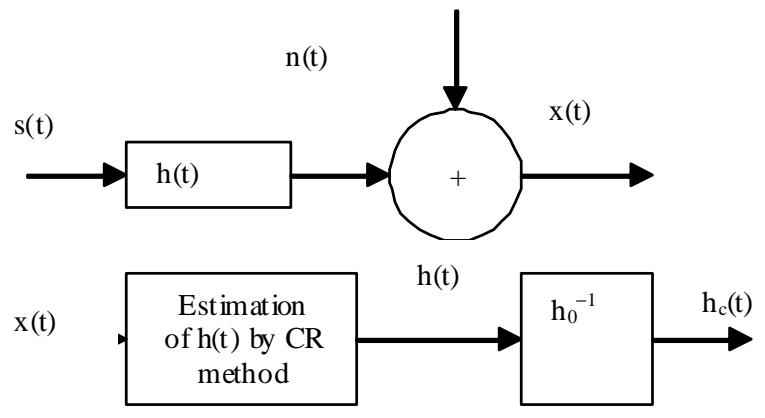

Fig. 3: Estimation of propagation channel $\mathrm{s}(\mathrm{t})$ : Transmitted signal BPSK $\mathrm{n}(\mathrm{t})$ : Additive noise $h(t)$ : Combined filter $\left[h(t)=h_{0}(t) * h_{c}(t)\right]$ 


\section{RESULTS AND DISCUSSION}

Figure 4 shows the estimated impulse response of the propagation channel for COST-207 $7^{[4]}$. Figure 5 shows the relative error estimation for training method and blind method.

Now, we will explore a semi-blind system based on the exploitation of the advantages of blind and nonblind systems in purpose to increase system efficiency. The system was first introduced by ${ }^{[5]}$, where they have exploited the notion of energy in the band. Our approach lies in the weighting of non-blind and blind parts in the system.

Let $\mathrm{S} 1$ be the training sequence, the SIMO semiblind system is defined as:

$$
\left[\begin{array}{lr}
\mathrm{S}_{1} & 0 \\
0 & \mathrm{~S}_{1} \\
\mathrm{X}_{2} & -\mathrm{X}_{1}
\end{array}\right]\left[\begin{array}{l}
\mathrm{h}_{1} \\
\mathrm{~h}_{2}
\end{array}\right]=\left[\begin{array}{l}
\mathrm{Y}_{1} \\
\mathrm{Y}_{2}
\end{array}\right]
$$
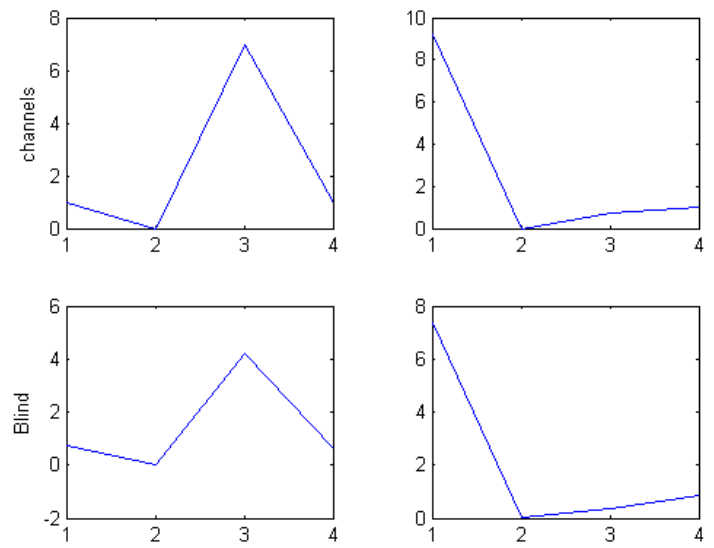

Fig. 4: Impulse response of channels COST-207 Mobil canal model for typical urban and rural area

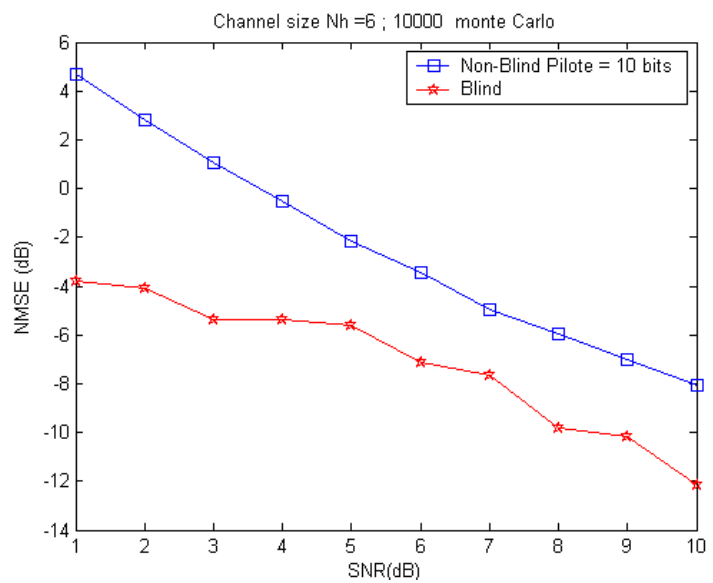

Fig. 5: Relative error for canal estimation
From Eq. 30, we can have:

$$
\left[\begin{array}{l}
h_{1} \\
h_{2}
\end{array}\right]=\left[\begin{array}{lr}
S_{1} & 0 \\
0 & S_{1} \\
X_{2} & -X_{1}
\end{array}\right]^{-1}\left[\begin{array}{l}
Y_{1} \\
Y_{2}
\end{array}\right]
$$

The simulation results of Eq. 31 give the relative error estimation of channels, shown in Fig. 6.

For the weighted semi-blind system we have:

$$
\left[\begin{array}{lr}
\alpha S_{1} & 0 \\
0 & \alpha S_{1} \\
\beta X_{2} & -\beta X_{1}
\end{array}\right]\left[\begin{array}{l}
h_{1} \\
h_{2}
\end{array}\right]=\left[\begin{array}{l}
Y_{1} \\
Y_{2}
\end{array}\right]
$$

where, $\alpha$ and $\beta=1-\alpha$, are weights. The solution for the identification of channels (Eq. 32) is given by:

$$
\left[\begin{array}{l}
h_{1} \\
h_{2}
\end{array}\right]=\left[\begin{array}{lr}
\alpha S_{1} & 0 \\
0 & \alpha S_{1} \\
\beta X_{2} & -\beta X_{1}
\end{array}\right]^{-1}\left[\begin{array}{l}
Y_{1} \\
Y_{2}
\end{array}\right]
$$

The simulation results of Eq. 33 for semi-blind system with training signal size $\mathrm{Nt}=26$ bits, is shown in Fig. 7.

The Fig. 8 shows the estimation error of channels for different pilot length. $\mathrm{Nt}=16$ bits for semi-blind method and $\mathrm{Nt}=26$ bits for Non-blind method.

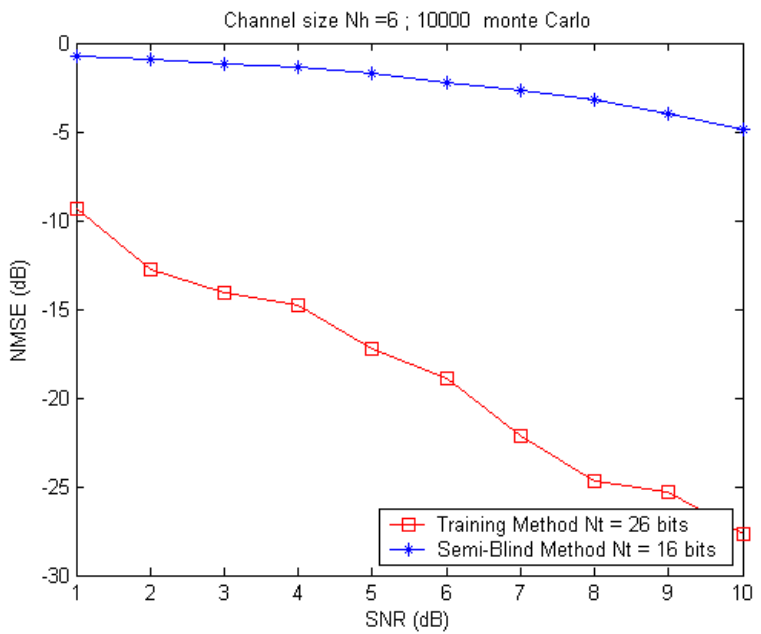

Fig. 6: Relative error for canal estimation equation error semi-blind system estimation for $\mathrm{Nt}=26$ bits 


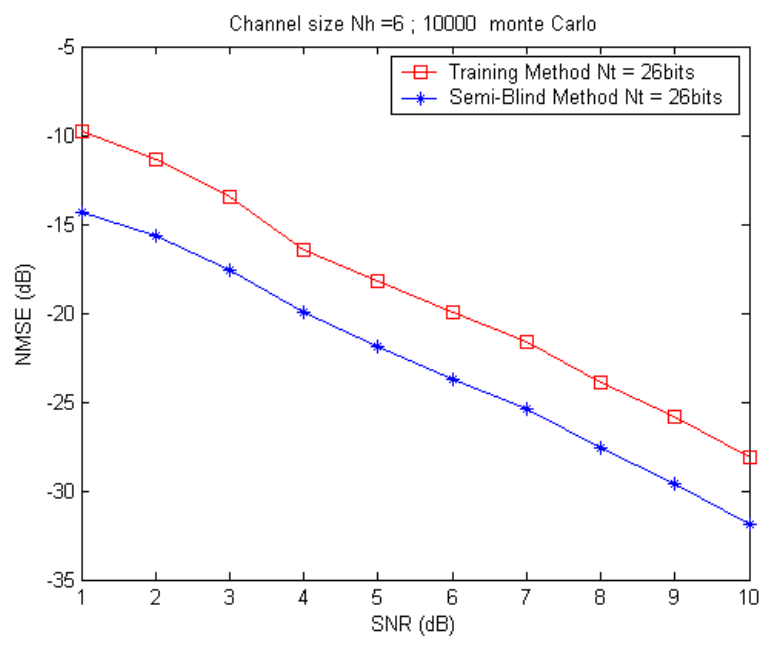

Fig. 7: Error weighted semi-blind system estimation for $\mathrm{Nt}=26$ bits

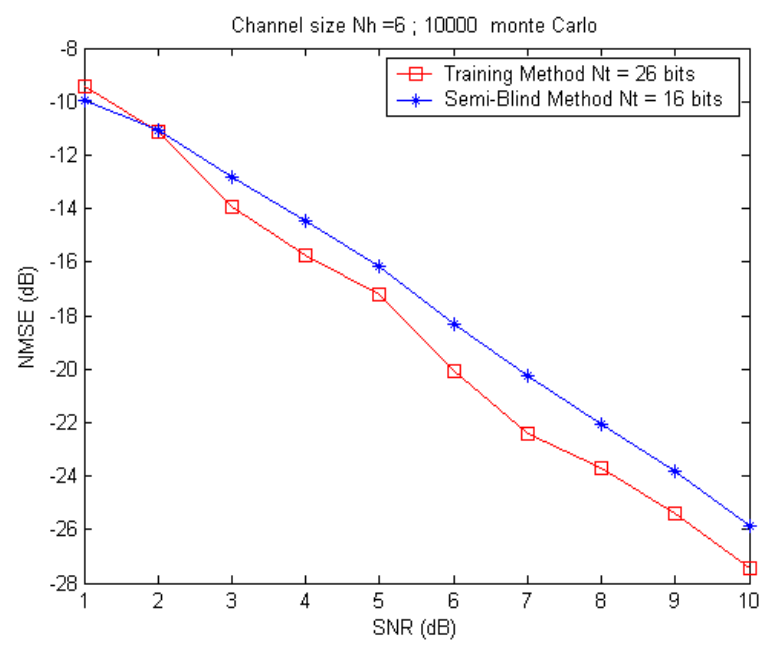

Fig. 8: Error system identification for: Semi-blind $\mathrm{Nts}=16$ bits, Non-Blind $\mathrm{Nt}=26$ bits

\section{CONCLUSION}

In this study, we have addressed the problem of blind channel and semi-blind system identification, based on the Cross-Relation method with the exploitation of the linearization of the GMSK signal used in GSM systems. The simulation results show great potential of semi-blind identification algorithms, since we have used no extra antenna or over-sampling the received signal. This method is of great importance since we can use 16 bits in the midamble of the GSM burst signal to transmit information; the gain is about $10 \%$ in system efficiency.

\section{REFERENCES}

1. Abed-Meraim, K., W. Qiu and Y. Hua, 1997. Blind system identification. Proc. IEEE., 85: 1310-1322. DOI: $10.1109 / 5.622507$

2. Ding, Z. and G. Li, 1998. Single channel blind equalization for GSM cellular systems. IEEE J. Select. Areas Commun., 16: 1493-1505. DOI: 10.1109/49.730456

3. Aïssa-El-Bey, A., M. Grebici, K. Abed-Meraim and A. Belouchrani, 2003. Blind system identification using cross-relation methods: further results and developments. Proceeding of the 7 th International Symposium on Signal Processing and its Applications, July, Paris, France, pp: 649-652. DOI: 10.1109/ ISSPA. 2003.1224787

4. Hoeher, P., 1992. A statistical discrete-time model for the wssus multipath channel. IEEE Trans. Vehicle Technol., 41: 461-468. DOI: 10.1109/25.182598

5. Joham, P., T.P. Krauss and M.D. Zoltowski, 1999. Channel estimation and equalization for GSM with multiple antennas. Proceeding of the IEEE 49th Vehicular Technology Conference, May 16-19, Houston, USA., pp: 1116-1120. DOI: 10.1109/VETEC.1999.780521 